\title{
Flower-like CuO synthesized by CTAB-assisted hydrothermal method
}

\author{
YUNLING ZOU*, YAN LI, NAN ZHANG and XIULIN LIU \\ College of Science, Civil Aviation University of China, Tianjin 300300, P.R. China
}

MS received 9 December 2009

\begin{abstract}
Flower-like $\mathrm{CuO}$ nanostructures have been synthesized by cetyltrimethylammonium bromide (CTAB)-assisted hydrothermal method. Here, $\mathrm{CuCl}_{2} \cdot 2 \mathrm{H}_{2} \mathrm{O}$ was used as copper raw material, and sodium hydroxide was used as precipitate. The resulting $\mathrm{CuO}$ powders were characterized by $\mathrm{X}$-ray diffraction (XRD) and field emission scanning electron microscopy (FESEM). X-ray diffraction (XRD) pattern exhibited the nanocrystalline nature with monoclinic structure for the as-synthesized nanostructures. FESEM images indicated that the flower-like $\mathrm{CuO}$ nanostructures are composed of many interconnected nanosheets in size of several micrometres in length and width and $60-80 \mathrm{~nm}$ in thickness. The possible formation mechanism of flower-like $\mathrm{CuO}$ nanostructures was discussed.
\end{abstract}

Keywords. CuO; flower; nanostructures; CTAB; hydrothermal method.

\section{Introduction}

Copper oxide $(\mathrm{CuO})$ is a narrow band gap $(E=1.2 \mathrm{eV})$ $p$-type semiconductor and has received considerable attention due to its potential applications in many fields, such as solar cells (Musa et al 1998), magnetic storage media (Dar et al 2008), superconductors (MacDonald 2001), lithium batteries (Morales et al 2005), heterogeneous catalysts (Chen et al 2008), and so on. For the properties of semiconductors depending on their size, shape and crystalline structure, the control of the shape and size of the semiconductors has become more important. Recently, much effort has been devoted to synthesizing unique $\mathrm{CuO}$ nanostructures, such as rods (Xu et al 2002), robbons (Liu and Zeng 2004; Gao et al 2009), wires (Su et al 2007), belts (Zhang et al 2008b), sheets (Zheng et al 2007), platelets (Zarate et al 2007), needles (Dar et al 2008), and tubes (Cho and Huh 2008). As one of the novel structures, flower-like $\mathrm{CuO}$ was expected to offer some exciting opportunities for some potential applications on electrochemistry (Pan et al 2007), sensors (Teng et al 2008), catalysis (Vaseem et al 2008), and field emission ( $\mathrm{Yu}$ et al 2008). So far, a variety of approaches to fabricating flower-like $\mathrm{CuO}$ nanostructures have been developed, such as hydrothermal (Yang et al 2007; Teng et al 2008), solution-immersion (Pan et al 2007), hydrolysis (Zhu et al 2007), microwave-hydrothermal (Volanti et al 2007; Xia et al 2009), chemical precipitation (Zhang et al 2008a), thermal oxidation ( $\mathrm{Yu}$ et al 2008) and solution-phase route ( $\mathrm{Yu}$ et al 2009). Teng et al (2008) synthesized the flower-like $\mathrm{CuO}$ nanostructures by

\footnotetext{
*Author for correspondence (zouyunling1999@126.com)
}

hydrothermal process using copper threads as precursor and pointed out that the flower-like $\mathrm{CuO}$ nanostructures are made of three structures: the nanocrystals, the petals, and the assembly of the petals. Zhu et al (2007) reported a facile route for synthesis of the flower-like $\mathrm{CuO}$ nanostructures composed of many interconnected needle-like crystallites by hydrolyzing of $\mathrm{Cu}(\mathrm{OAc})_{2}$ solution without any surfactants. Rose-like nanoarchitectures $\mathrm{CuO}$ composed of wide nanosheets have been prepared by a mild solution-phase route without the utility of the templates, additives or external magnetic field (Yu et al 2009).

Surfactant is conventionally used as morphologydirecting agent to obtain nanostructural-conducting polymers due to its ability to form thermodynamically stable aggregates of inherently nanoscale dimensions (Jang and Oh 2002; Andrew et al 2003). CTAB is a useful surfactant that has been widely used in fabricating the nanomaterials to control the morphology. Recently CTABassisted hydrothermal technique has emerged as an attractive technique to investigate the synthesis of zinc oxide nanostructures. There are also some reports about the preparation of $\mathrm{CuO}$ nanostructures by using $\mathrm{CTAB}$ assisted hydrothermal technique. Cao and co-workers (Cao et al 2003) reported CTAB-assisted hydrothermal synthesis of $\mathrm{CuO}$ of various morphologies such as rod-like spheroidal, hexahedron structures, and other irregular structures. $\mathrm{CuO}$ shuttle-like nanocrystals were synthesized by the hydrolysis of cupric acetate $\left(\mathrm{Cu}\left(\mathrm{CH}_{3} \mathrm{COO}\right)_{2}\right.$. $\mathrm{H}_{2} \mathrm{O}$ ) via a CTAB-assisted hydrothermal route at low temperature (Zhang et al 2006). In this work, we reported the fabrication of flower-like $\mathrm{CuO}$ nanostructures by CTAB-assisted hydrothermal method and its characterization by X-ray diffraction (XRD). The morphology of flower-like $\mathrm{CuO}$ nanostructures was observed by field 
emission scanning electron microscopy (FESEM). The possible formation mechanism of flower-like $\mathrm{CuO}$ nanostructures was discussed.

\section{Experimental}

\subsection{Chemicals}

Analytical grade copper chloride dihydrate $\mathrm{CuCl}_{2} \cdot 2 \mathrm{H}_{2} \mathrm{O}$ and sodium hydroxide $\mathrm{NaOH}$ were used as precursors, purchased from Tianjin Tianda Chemical Experiment Factory. Cetyltrimethylammonium bromide $\left(\mathrm{C}_{19} \mathrm{H}_{42} \mathrm{BrN}\right)$ of analytical grade was purchased from Kewei Company of the Tianjin University. All the chemicals were directly used without further purification. Deionized water was used throughout.

\subsection{Sample preparation}

In a typical synthesis, the starting solution of copper $\left(0.25 \mathrm{~mol} \mathrm{l}^{-1}\right)$ was prepared by dissolving $0.8524 \mathrm{~g}$ ( $5 \mathrm{mmol}) \mathrm{CuCl}_{2} \cdot 2 \mathrm{H}_{2} \mathrm{O}$ in $20 \mathrm{ml}$ deionized water. Subsequently, the $\mathrm{CuCl}_{2}$ solution was slowly dropped into the $50 \mathrm{ml}$ of $\mathrm{NaOH}$ solution $\left(3 \mathrm{~mol} \mathrm{l}^{-1}\right)$ under vigorous stirring, and a blue-coloured precursor was obtained. $1 \mathrm{~g}$ CTAB (3 mmol) was added to the blue-coloured precursor and stirred vigorously for $30 \mathrm{~min}$ at $50^{\circ} \mathrm{C}$ to ensure complete dissolution of CTAB. This reaction solution was then transferred to a $100 \mathrm{ml}$ Teflon-lined stainless steel autoclave and heated at $150^{\circ} \mathrm{C}$ for $12 \mathrm{~h}$ in an electric oven. After reaction, the autoclave was allowed to cool to room temperature. The obtained black precipitate was centrifuged and washed thoroughly with deionized water and ethanol. Then, the precipitate was dried in drying oven at $60^{\circ} \mathrm{C}$ for $24 \mathrm{~h}$. Finally, the products were calcined in a furnace with an air atmosphere at $500^{\circ} \mathrm{C}$ for $2 \mathrm{~h}$.

\subsection{Instrumentation}

Power X-ray diffraction (XRD) was measured on a DX2000 X-ray diffractometer with $\mathrm{CuK} \alpha$ radiation $(\lambda=0.1542 \mathrm{~nm})$, and the tests were under accelerated voltage of $30 \mathrm{kV}$ and current of $25 \mathrm{~mA}$. Field emission scanning electron microscopy (FESEM) images and energy dispersive spectrum (EDS) were obtained by FEI Nanosem 430 FESEM and Genesis XM2 APEX 60SEM respectively.

\section{Results and discussion}

\subsection{The structural characterization of $\mathrm{CuO}$}

The structure and chemical composition of the sample were confirmed by an X-ray diffraction. The typical XRD patterns of the samples synthesized via CTAB-assisted hydrothermal method at $150^{\circ} \mathrm{C}$ for $12 \mathrm{~h}$ are shown in figure 1. In the XRD pattern, compared with the standard diffraction peaks from JCPDS card no. 80-1917, the peaks located at $2 \theta$ values of $30-80^{\circ}$ can be indexed to the characteristic diffractions of monoclinic phase $\mathrm{CuO}$ $(a=4.689 \AA, c=5.132 \AA)$. The peak intensities and widths clearly indicated that the sample was highly crystalline in nature. Compared with the standard diffraction patterns, there are no other characteristic peaks observed belonging to impurities indicating that all the products were phase-pure.

Energy dispersive analysis of X-ray (EDAX) on the obtained as-prepared $\mathrm{CuO}$ sample was performed using the field emission scanning electron microscope (FESEM). EDAX spectra (shown in figure 2) clearly demonstrates

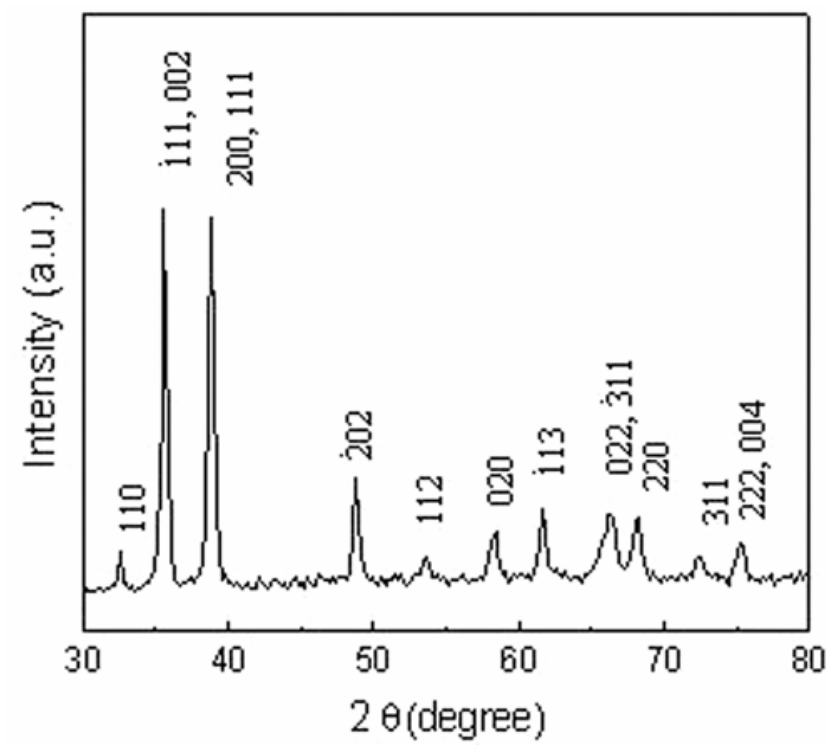

Figure 1. XRD pattern of flower-like $\mathrm{CuO}$ nanostructures synthesized at $150^{\circ} \mathrm{C}$ for $12 \mathrm{~h}$.

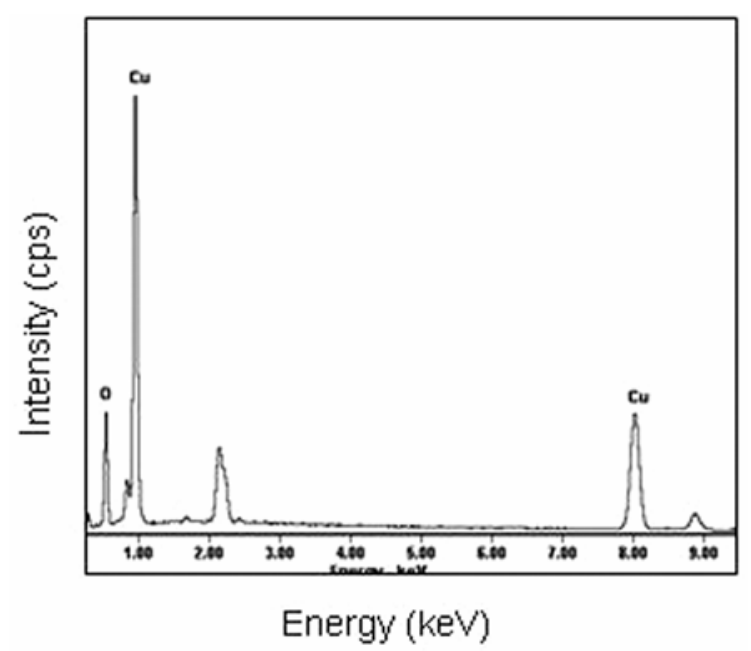

Figure 2. EDS spectra of flower-like $\mathrm{CuO}$ nanostructures. 

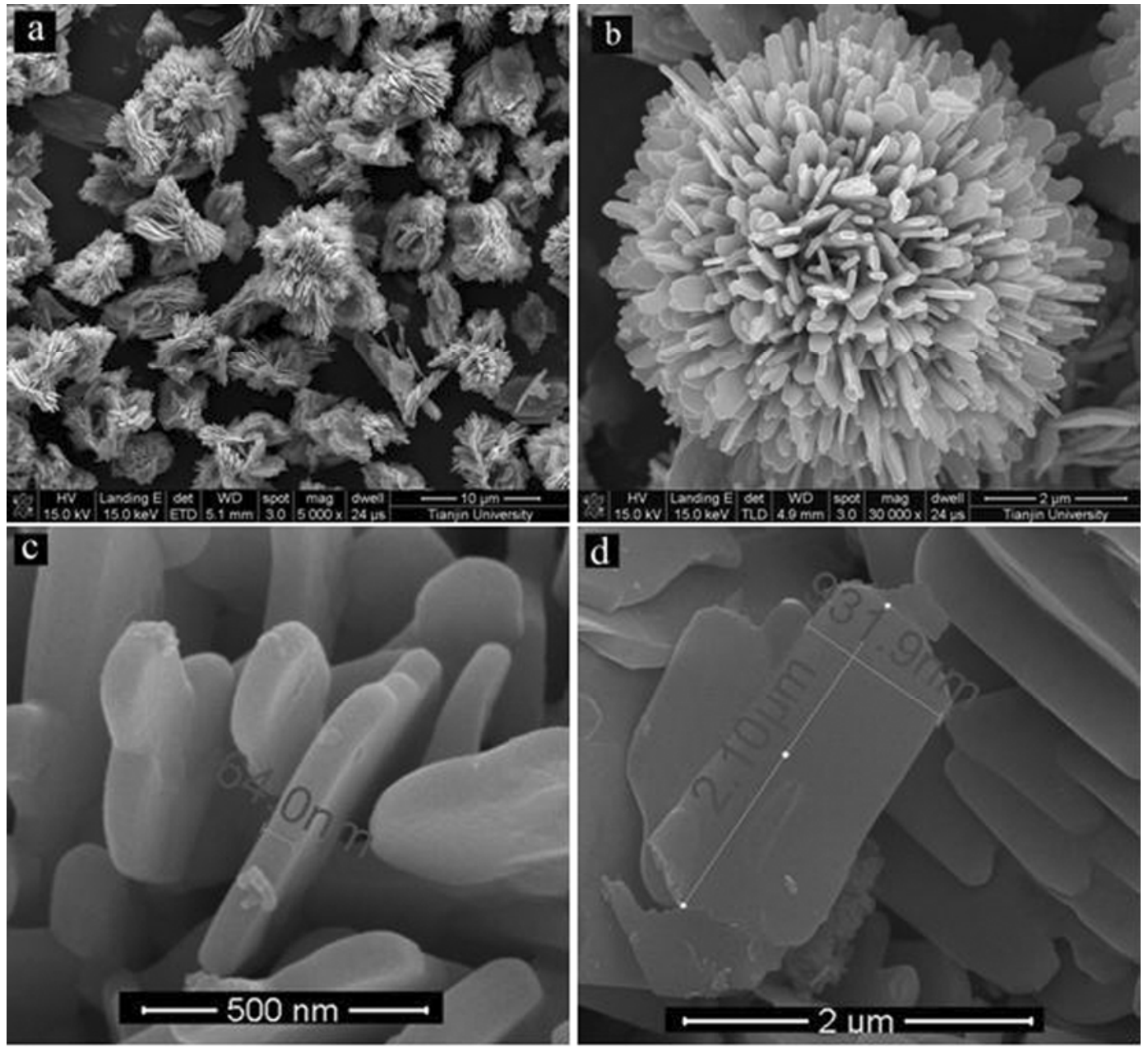

Figure 3. FESEM images of flower-like $\mathrm{CuO}$ nanostructures

the presence of $\mathrm{Cu}$ and $\mathrm{O}$ peaks and quantitative analysis reveals that $\mathrm{Cu}$ and $\mathrm{O}$ are in a stoichiometry with $1: 1$ ratio. Therefore, it was obvious that the sample is composed of a pure monoclinic phase $\mathrm{CuO}$, which is consistent with the XRD pattern.

\subsection{The morphology of product and formation mechanism}

The morphology of the as-prepared $\mathrm{CuO}$ sample was analysed by the FESEM as shown in figure 3. The lower magnification image in figure $3 \mathrm{a}$ indicates that the obtained $\mathrm{CuO}$ is composed of flower-like structure. The diameter of the micro-flower is about $6 \mu \mathrm{m}$. A detailed side view on the individual flower-like $\mathrm{CuO}$ particle can be observed from the higher magnification image (figure $3 b$ ), which clearly shows that the $\mathrm{CuO}$ flowers with spherical symmetry are composed of many interconnected wide nanosheets. The thickness of the nanosheets is in average of 60-80 $\mathrm{nm}$ (shown in figure 3c). Figure $3 \mathrm{~d}$ shows a typical image of a piece of the leaves forming the flower-like structures, which clearly shows that the width of the nanosheets is about $932 \mathrm{~nm}$ and the length is about $2 \cdot 10 \mu \mathrm{m}$ at the higher magnification. FESEM images in figures $3 b-d$ indicate that the nanosheets were first formed in the beginning and then they interconnect each other to form the flower-like $\mathrm{CuO}$ nanostructures. From figure $3 b$, we can also see that the nanosheets are aligned perpendicularly to the flower surface pointing toward a common centre.

According to references, the formation mechanisms of the flower-like $\mathrm{CuO}$ nanostructures were different when different preparation methods were used. Zhu et al (2007) obtained the flower-like $\mathrm{CuO}$ nanostructures composed of many interconnected needle-like crystallites by hydrolysing of $\mathrm{Cu}(\mathrm{OAc})_{2}$ solution without any surfactants. They analyzed that the morphology of $\mathrm{CuO}$ crystallites is depended on different growing rates of various crystal facets. The coordination number of $\mathrm{Cu}^{2+}$ generally keeps six in the hydrolysis reaction. Each $\mathrm{Cu}^{2+}$ would be surrounded by six water molecules due to the solvating action when copper salt dissolved in water, in which four water molecules surrounded $\mathrm{Cu}^{2+}$ to form square structure, and other two water molecules located at its axis. 
Teng et al (2008) synthesized the flower-like $\mathrm{CuO}$ nanostructures by hydrothermal process using copper threads as precursor. They investigated the influences of hydrothermal temperature and hydrothermal time on the nanostructures and reported that the formation of the flowerlike structure was controlled not only by the growth thermodynamics, but also by the growth kinetics. Yu et al (2008) prepared the flower-like $\mathrm{CuO}$ nanostructures by reaction between a $\mathrm{Cu}$ plate and a $\mathrm{KOH}$ solution at room temperature. They speculated that the nanoflower was a representative morphology of spherulite formed by radiating growth from a centre or a number of centres and the $\left[\mathrm{Cu}(\mathrm{OH})_{4}\right]^{2-}$ complexes played a key role in the growth of nanoflowers.

In our work, we reported the preparation of by cetyltrimethylammonium bromide (CTAB)-assisted hydrothermal method. CTAB has been systematically studied in the synthesis of mesostructured materials and may form spherical, cylindrical micelle, or even higher-order phases depending on the solution conditions (Fendler and Fendler 1975). Here, we think that CTAB serves as a template in the formation of flower-like $\mathrm{CuO}$ nanostructures. The formation of flower-like $\mathrm{CuO}$ nanostructures in the reaction system could be represented by the following reactions

$$
\begin{aligned}
& \mathrm{Cu}^{2+}+4 \mathrm{OH}^{-} \leftrightarrow\left[\mathrm{Cu}(\mathrm{OH})_{4}\right]^{2-}, \\
& \mathrm{Cu}(\mathrm{OH})_{4}{ }^{2-} \leftrightarrow \mathrm{CuO}+\mathrm{H}_{2} \mathrm{O}+2 \mathrm{OH}^{-} .
\end{aligned}
$$

The $\left[\mathrm{Cu}(\mathrm{OH})_{4}\right]^{2-}$ anion can be considered as a precursor entity for the formation of $\mathrm{CuO}$ in this study. We believe that inorganic precursor $\mathrm{Cu}(\mathrm{OH})_{4}^{2-}$ and cationic surfactant CTAB form $\mathrm{CTA}^{+}-\left[\mathrm{Cu}(\mathrm{OH})_{4}\right]^{2-}$ ion pairs at the beginning of the CTAB-assisted hydrothermal process. Since CTAB is a kind of strong-acid-weak-base salt, it can accelerate the ionization of $\left[\mathrm{Cu}(\mathrm{OH})_{4}\right]^{2-}$. The $\mathrm{CTA}^{+}-\left[\mathrm{Cu}(\mathrm{OH})_{4}\right]^{2-}$ ion pairs form combination of $\mathrm{CTAB}$ and $\mathrm{CuO}$. In addition to the general confirmation of $\mathrm{CuO}$ phase, the XRD patterns also provide information on crystal orientations (Chang and Zeng 2004). From the XRD pattern of figure 1, we know that low miller-indexed ((002) and (200)) reflections are the strongest. It indicated that the $\mathrm{CuO}$ nanosheets were first formed with the oriented growth of the $\left[\mathrm{Cu}(\mathrm{OH})_{4}\right]^{2-}$ along (002) and (200) direction in the beginning (shown in figure $3 \mathrm{~d}$ ). Therefore a possible formation process of the flower-like $\mathrm{CuO}$ nanostructures could be purposely divided into several processes: (1) formation of $\mathrm{CTA}^{+}-\left[\mathrm{Cu}(\mathrm{OH})_{4}\right]^{2-}$ ion pairs; (2) growth of the $\mathrm{CuO}$ nanosheets (shown in figure 3d); and (3) formation of the flower-like nanostructures (shown in figure $3 b$ ).

\section{Conclusions}

Flower-like $\mathrm{CuO}$ nanostructures have been synthesized by cetyltrimethylammonium bromide (CTAB)-assisted hydrothermal method with $\mathrm{CuCl}_{2} \cdot 2 \mathrm{H}_{2} \mathrm{O}$ and sodium hydroxide as raw materials. X-ray diffraction (XRD) pattern exhibited the nanocrystalline nature with monoclinic structure for the as-synthesized nanostructures. FESEM images indicated that the flower-like $\mathrm{CuO}$ nanostructures are composed of many interconnected nanosheets in size of several micrometres in length and width and $60-80 \mathrm{~nm}$ in thickness. The nanosheets were aligned perpendicularly to the flower surface pointing toward a common centre. A possible formation mechanism is proposed: the nanosheets were first formed in the beginning and then the nanosheets interconnect each other to form the flower-like $\mathrm{CuO}$ nanostructures.

\section{Acknowledgements}

This study was supported by the Natural Science Foundation of Tianjin (no. 09JCYBJC04200). We are also grateful to the Research Fund of Civil Aviation University of China (no. 07KYS05) and the Centre of Analysis and Measurement of Tianjin University.

\section{References}

Andrew D W, Carswell Edgar A, O'Rear and Brian P Grady 2003 J. Am. Chem. Soc. 12514793

Cao M H, Hu C W, Wang Y H, Guo Y H, Guo C X and Wang E B 2003 Chem. Commun. 151884

Chang Y and Zeng H C 2004 Cryst. Growth Des. 4397

Chen L J, Li L P and Li G S 2008 J. Alloys Compd. 464 532

Cho Y S and Huh Y D 2008 Bull. Korean Chem. Soc. 29 2525

Dar M A, Kim Y S, Kim W B, Sohn J M and Shin H S 2008 Appl. Surf. Sci. $\mathbf{2 5 4} 7477$

Fendler J H and Fendler E J 1975 Catalysis in micellar and macromolecular systems (New York: Academic Press)

Gao P, Chen Y J, Lv H J, Li X F, Wang Y and Zhang Q 2009 Int. J. Hydrogen Energy 343065

Jang J and Oh J H 2002 Chem. Commun. 192200

Liu B and Zeng H C 2004 J. Am. Chem. Soc. 1268124

MacDonald A H 2001 Nature $\mathbf{4 1 4} 409$

Morales J, Sánchez L, Martín F, Ramos-Barrado J R and Sánchez M 2005 Thin Solid Films 474133

Musa A O, Akomolafe T and Carter M J 1998 Solar Energy Mater. Solar Cell 51305

Pan Q M, Jin H Z, Wang H B and Yin G P 2007 Electrochim. Acta $\mathbf{5 3} 951$

Su Y K, Shen C M, Yang H T, Li H L and Gao H J 2007 Trans. Nonferrous Met. Soc. China 17783

Teng F, Yao W Q, Zheng Y F, Ma Y T, Teng Y, Xu T G, Liang S H and Zhu Y F 2008 Sens. Actuators B134 761

Vaseem M, Umar A, Hahn Y B, Kim D H, Lee K S, Jang J S and Lee J S 2008 Catal. Commun. 1011

Volanti D P, Keyson D, Cavalcante L S, Simões A Z, Joya M R, Longo E, Varela J A, Pizani P S and Souza A G 2008 J. Alloys Compd. 459537

Xia J X, Li H M, Luo Z J, Shi H, Wang K, Shu H M and Yan Y S. 2009 J. Phys. Chem. Solids 701461 
Xu C K, Liu Y K, Xu G D and Wang G H 2002 Mater. Res. Bull. 372365

Yang Z H, Xu J, Zhang W X, Liu A P and Tang S P 2007 J. Solid State Chem. 1801390

Yu L G, Zhang G M, Wu Y, Bai X and Guo D Z 2008 J. Cryst. Growth 3103125

Yu Y L and Zhang J Y 2009 Mater. Lett. 631840

Zarate R A, Hevia F, Fuentes S, Fuenzalida V M and Zúñiga A 2007 J. Solid State Chem. 1801464
Zhang H X, Feng J and Zhang M L 2008a Mater. Res. Bull. 43 3221

Zhang X J, Wang G F, Liu X W and Wu H Q 2008b Mater. Chem. Phys. 112726

Zhang Y G, Wang S T, Li X B, Chen L Y, Qian Y T and Zhang Z D 2006 J. Cryst. Growth 291196

Zheng L K and Liu X J 2007 Mater. Lett. 612222

Zhu J W, Bi H P, Wang Y P, Wang X, Yang X J and Lu L D 2007 Mate. Lett. 615236 